\title{
ENCHENTES DO RIO URUGUAI NO RIO GRANDE DO SUL ENTRE 1980 E 2005: UMA ANÁLISE GEOGRÁFICA
}

\section{Flooding in the Uruguay River in Rio Grande do Sul During 1980 and 2005: a Geographical Analysis}

\author{
Eléia Righi \\ Instituto de Geociências - Programa de Pós-Graduação em Geografia \\ Universidade Federal do Rio Grande do Sul \\ Porto Alegre/RS - Brasil \\ leiarighi@yahoo.com.br \\ Luis Eduardo de Souza Robaina \\ Departamento de Geociências - Universidade Federal de Santa Maria \\ Santa Maria/RS - Brasil \\ lesrobaina@yahoo.com.br
}

RESUMO: Os municipios que margeiam o rio Uruguai têm sido atingidos frequentemente por enchentes que deixam grande número de pessoas desabrigadas e, em algumas vezes, até vítimas fatais. Neste sentido, o presente estudo teve como objetivo central realizar um levantamento da ocorrência de enchentes nos municípios que margeiam o rio Uruguai no Estado do Rio Grande do Sul no período compreendido entre 1980 a 2005. Os objetivos especificos consistiram em apresentar de forma cartográfica os municípios nos quais ocorreram tais eventos, como também, pretendeu-se relacionar cada evento de enchente com a quantidade pluviométrica diária coletada em dez estações meteorológicas distribuídas nas sub-bacias hidrográficas do rio Uruguai. Os dados referentes às enchentes foram pesquisados junto ao acervo do jornal Zero Hora e no Diário Oficial do Estado do Rio Grande do Sul; os dados pluviométricos foram obtidos na Fundação Estadual de Pesquisa Agropecuária (FEPAGRO) e junto a Agência Nacional das Águas (ANA). As análises dos dados pluviométricos foram realizadas através da técnica estatística paramétrica. A análise das precipitações das 10 Estações meteorológicas e os municípios atingidos em cada ocorrência de enchente foi realizada observando primeiramente a abrangência do evento e posteriormente a quantidade de chuvas nas Estações pluviométricas significativas, estando apresentados em cartogramas. Dessa forma, o trabalho contribuiu como fonte descritiva histórica dos eventos de inundações, os quais podem, direta ou indiretamente, interferir na maioria das atividades humanas realizadas. O conhecimento do regime pluviométrico em relação à ocorrência de enchentes permite que a população planeje os espaços e utilize os recursos hídricos de forma mais eficiente e racional.

Palavras-Chave: Rio Uruguai. Enchentes. Análise Pluviométrica.

ABSTRACT: The municipalities in the Uruguay river margins has been frequently reached by flooding which leave a large number of uncovered people and, sometimes, fatal victims. In this sense, the present study has the central subject to carry on a study of number of flooding occurrences in the municipalities'emarginated by Uruguay River in the Rio Grande do Sul State between the years of 1980 and 2005. The specific subjects are consisted in to present the municipalities where those events occurred in a cartographic manner, and it is intended to relate each flooding event to the daily collected pluviometer data in 10

Sociedade \& Natureza, Uberlândia, 22 (1): 35-54,abr. 2010 
Enchentes do Rio Uruguai no Rio Grande do Sul entre 1980 e 2005: uma análise geográfica Eléia Righi, Luis Eduardo de Souza Robaina

Meteorological Stations distributed in Uruguay hydrographic sub-basins as well. Data referring to flooding were researched Zero Hora and Diário Oficial do Estado do Rio Grande do Sul collection; pluviometer data was obtained in Fundação Estadual de Pesquisa Agropecuária (FEPAGRO) and Agência Nacional das Águas (ANA). The pluviometer data analyses were undertaken by means of parametric statistic technique. The 10 Meteorological Stations precipitation analysis along the affected in each flooding occurrence was carried on observing at first the event range and at last the rain quantity in the significant Meteorological Station, being presented as cartograms. In this way, the present work aims to contribute to the understanding of flooding events that can, directly or indirectly, to interfere in most of the human activities accomplished. The knowledge of the pluviometric regime in relation to occurrence of flooding allow the population to think out the spaces ant to use the hydric resources in a more efficient and rational manner.

Keywords: Uruguay River. Flooding. Pluviometric Analysis.

\section{INTRODUÇÃO}

Embora as inundações sejam fenômenos de ordem natural, a ação antrópica, interferindo ao longo do tempo, seja nas áreas urbanas, seja nas áreas rurais do rio Uruguai no Estado do Rio Grande do Sul, tem contribuído, consideravelmente, para sua maior frequência, agressividade e expansão.

A Secretaria Nacional de Defesa Civil ressalta que as ocorrências de inundações aumentam significativamente a dívida social de uma região, tendo em vista que as pessoas de menor poder aquisitivo são a imensa maioria das vítimas, por estarem habitando áreas de risco e, muitas vezes não terem a percepção global dos riscos a que estão expostas.

Reckziegel e Robaina (2007) apontam mais de 25 eventos registrados entre 1980 e 2005 nos municípios que margeiam o rio Uruguai. Muitas cidades ribeirinhas desse grande rio, já perderam centenas de moradias que ficaram submersas, assim como destruição de lavouras, estradas e pontes.

Dessa forma, o presente estudo teve como objetivo realizar um levantamento histórico dos municípios nos quais ocorreram eventos de inundações do rio Uruguai no Estado do Rio Grande do Sul nas duas últimas décadas. Além disso, relacionar com a quantidade pluviométrica diária coletada em dez estações meteorológicas distribuídas nas sub-bacias hidrográficas do rio Uruguai.

\section{RIO URUGUAI: Localização e Caracterização}

O rio Uruguai (FIGURA 1) é o segundo sistema fluvial da bacia do rio da Prata em importância. Desde a confluência dos rios Pelotas e Canoas, a montante, até sua confluência com rio Paraná assume a direção leste-oeste, dividindo os estados do Rio Grande do Sul e Santa Catarina. Após a sua confluência com o rio Peperi-Guaçu, escoa na direção sudoeste, servindo de fronteira entre o Brasil e a Argentina. Após receber a afluência do rio Quaraí, que limita o Brasil e o Uruguai, na região sudoeste do Estado do Rio Grande do Sul, toma a direção sul, fazendo fronteira entre a Argentina e o Uruguai, até sua foz.

A $100 \mathrm{~km}$ a jusante da confluência do rio Canoas, isto é, a partir da foz do rio do Peixe inicia-se o rio Uruguai propriamente dito. Nos seus primeiros $400 \mathrm{~km}$ o rio Uruguai apresenta uma declividade de $0,5 \mathrm{metros} / \mathrm{km}$ e atinge uma cota de 150 metros em relação ao nível do mar (foz do rio Peperi-Guaçu). Embora poucos, os dados de largura do leito menor indicam sua variação na faixa de 250 metros a 650 metros (TUCCI, 1993). 


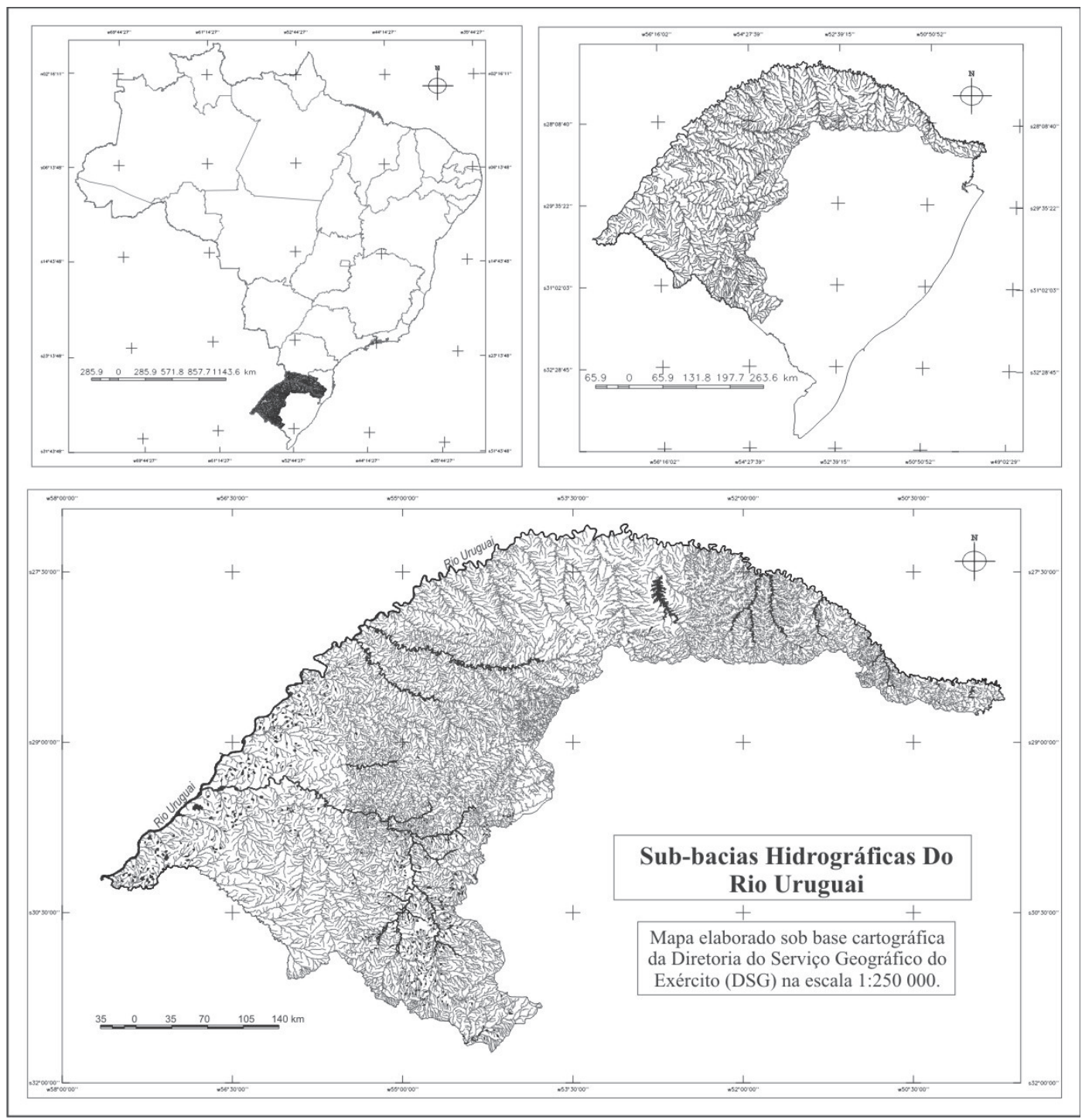

FIGURA 1: Localização da Bacia do Rio Uruguai no estado do RS.

O curso médio do rio Uruguai, até a localidade de Salto (Uruguai) abrange uma extensão aproximada de $570 \mathrm{~km}$. Seu principal afluente pertencente à margem esquerda é o Ibicuí, por ocupar uma maior área. A largura máxima do rio é 1200 metros em Uruguaiana e sua declividade se reduz para 0,10 metros/km (TUCCI, 1993).

Os restantes $325 \mathrm{~km}$ representam o curso inferior do rio Uruguai. Nos últimos $350 \mathrm{~km} \mathrm{a}$ navegação se verifica, no todo, para embarcação de 1,80 metros de calado e nos $190 \mathrm{~km}$ finais para embarcações de grande porte, dado que a profundidade mínima aí verificada é de 40 metros. No trecho francamente navegável $(350 \mathrm{~km})$ sua declividade média acha-se em torno de $3 \mathrm{~cm} / \mathrm{km}$ (TUCCI, 1993).

De acordo com Justus (1990, apud BASSO, 2004), esse rio, como seus afluentes, caracterizase por estar muito encaixado e formar meandros. A jusante de Porto Lucena, o rio Uruguai amplia seu vale, praticamente sem encaixamento, com feições que denotam significativa acumulação fluvial que aumenta em área em direção sul. 
Os principais afluentes do rio Uruguai dentro do Estado do Rio Grande do Sul (conforme FIGURA 2) são os rios Pelotas, Várzea, Ijuí, Piratinim, Ibicuí e Quaraí, sendo este último situado na fronteira com o Uruguai.

Por situar na extremidade meridional do Brasil, as sub-bacias apresentam amplitudes térmicas anuais, atingindo temperatura no entorno ou abaixo de $0^{\circ} \mathrm{C}$ durante o inverno, e dias quentes $\left(>30^{\circ} \mathrm{C}\right)$ e úmidos durante o verão. A região mais fria naturalmente esta situada nas maiores altitudes dos campos do alto da serra enquanto a região mais quente esta no extremo oeste do Estado.

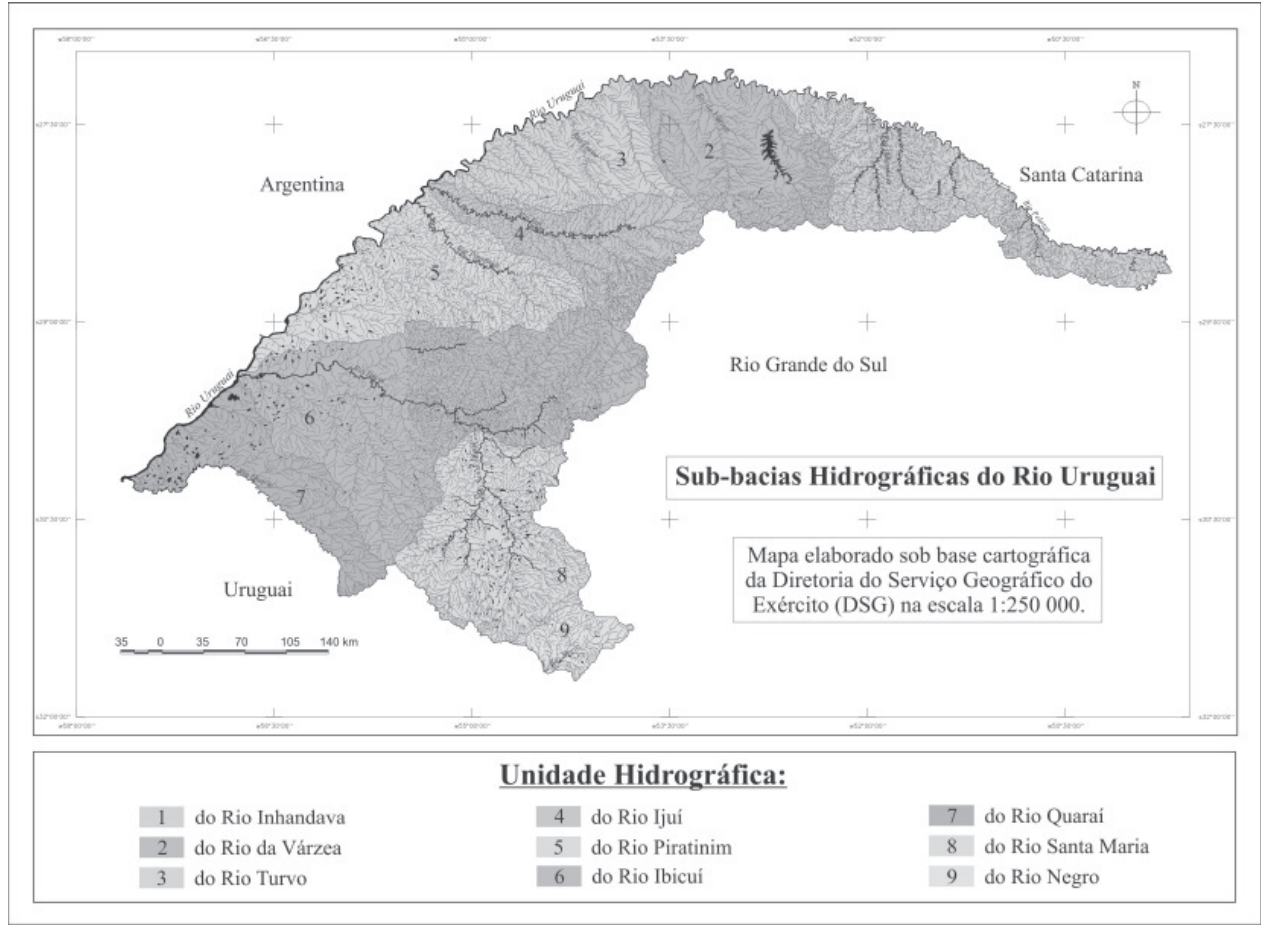

FIGURA 2: Unidades Hidrográficas do Rio Uruguai no Rio Grande do Sul.

Em relação às precipitações ocorridas na região Sul do Brasil, estas podem ser descritas como bem distribuídas, possuindo máximos, que variam entre $1250 \mathrm{~mm}$ e $2100 \mathrm{~mm}$ (NIMER, 1989).

As flutuações entre as bacias hidrográficas são de pequena magnitude, podendo-se notar uma tendência a índices de precipitação anuais crescentes no sentido Sul - Norte.

De maneira geral, nas sub-bacias hidrográficas do rio Uruguai podem ser individualizados três domínios morfoesculturais, a partir das características geológicas, estruturais e do modelado da superfície: o Escudo Sul-rio-grandense, formado de rochas cristalinas do Pré-cambriano; a Depressão Periférica, formada de rochas sedimentares da Bacia do Paraná e o Planalto Meridional, formado de rochas vulcânicas (RADAM/IBGE, 2003).

\subsection{Aspectos Sociais e Econômicos}

A região hidrográfica do rio Uruguai teve dois momentos de apropriação efetiva das terras, a primeira ocorreu na década de 1820 com a ocupação dos campos nativos e a formação das estâncias pastoris (latifúndios). Essa forma de distribuição caracterizou a região dos campos e deram origem a uma sociedade latifundiária, patriarcal e hierárquica de senhores, peões e escravos (SOUZA, 2000). 
Entre 1824 e 1875, chegaram os primeiros imigrantes alemães e italianos que se estabeleceram na encosta superior da serra nordeste e pelos vales dos rios próximos. Iniciou-se então a ocupação das áreas acidentadas, cobertas por matas e desprezadas pelos criadores de gado.

Em 1920, o processo de ocupação das terras do Rio Grande do Sul estava consolidado. Conforme destaca Souza (2000), as condições históricas de ocupação geraram duas regiões diferenciadas quanto ao uso do solo, estrutura fundiária e quanto à divisão político administrativa. A região norte, ocupada por colonos (principalmente imigrantes), caracteriza-se por pequenos municípios e pela pequena propriedade onde se desenvolveu a agricultura familiar.

Por outro lado, a região sul, que é composta de grandes municípios, grandes propriedades, pelo desenvolvimento da pecuária como principal atividade e dos produtos derivados dela.

Assim, a distribuição dos municípios as margens do rio Uruguai de jusante para montante, são os de menor área localizados mais a montante $\mathrm{e}$ os de maior à jusante.

\section{MATERIAIS E MÉTODOS}

O levantamento dos dados referentes à ocorrência de enchentes no rio Uruguai no Estado do Rio Grande do Sul, foi embasado nos trabalhos realizados por Reckziegel (2007), a qual utilizou duas fontes de dados para os 26 anos analisados: Diário Oficial e informações na imprensa escrita.

Os dados legais referem-se aos decretos de Situação de Emergência e de Estado de Calamidade Pública, tendo sido levantados junto à Defesa Civil do Estado do Rio Grande do Sul e nas publicações do Diário Oficial do Estado. O veículo de imprensa escolhido foi o jornal Zero Hora, no qual foram levantadas as reportagens que continham notícia a respeito da ocorrência de enchentes e outros desastres.

Foram levantados dados anuais, mensais e diários de precipitação de seis Estações meteorológicas (FIGURA 3), Quaraí, Uruguaiana, São Borja, Santa Rosa, Erechim e Ijuí, pertencentes à rede da Fundação Estadual de Pesquisa Agropecuária - FEPAGRO, disponibilizados na própria Fundação através de meio digital (CD).

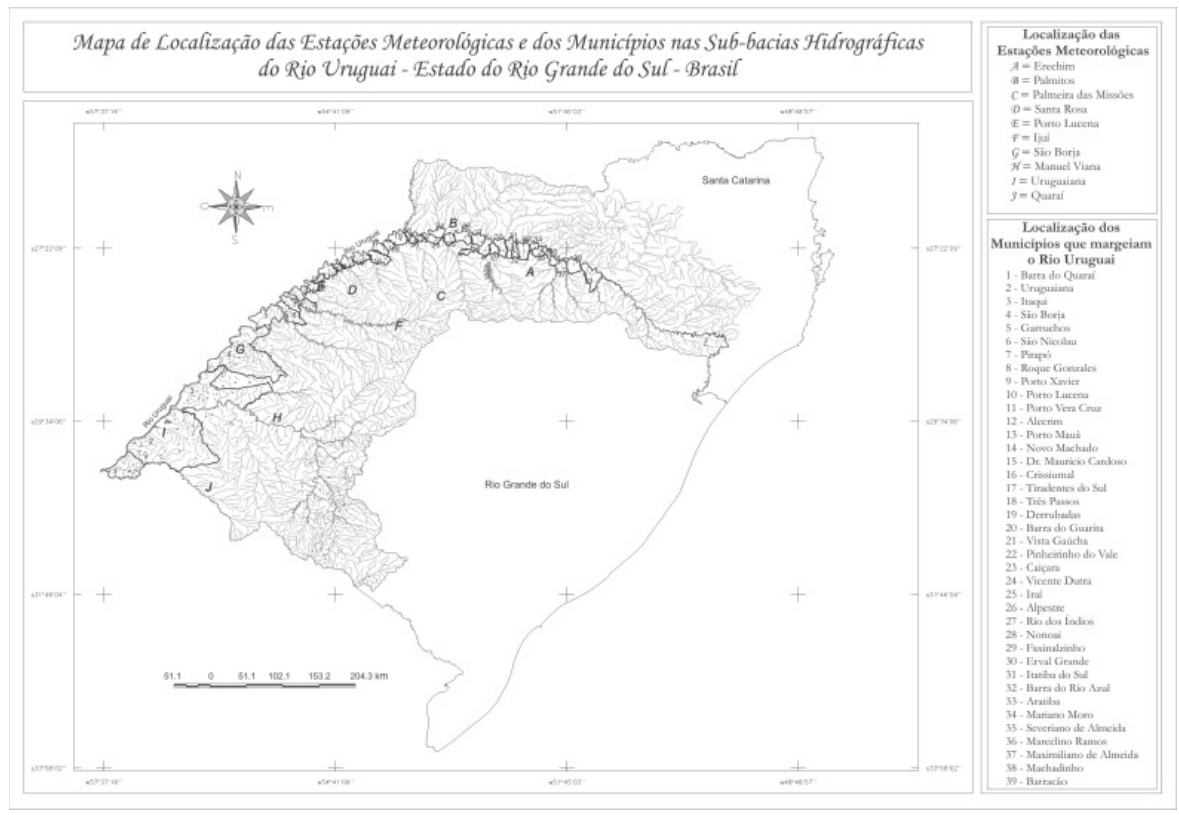

FIGURA 3: Localização das Estações Meteorológicas. 
Enchentes do Rio Uruguai no Rio Grande do Sul entre 1980 e 2005: uma análise geográfica

Eléia Righi, Luis Eduardo de Souza Robaina

Também foram coletados dados junto a Agência Nacional das Águas - ANA, de quatro Estações meteorológicas, Manoel Viana, Palmeira das Missões, Porto Lucena e Palmitos. Estes dados estão disponíveis no site da ANA - <www.ana.gov. br>.

Foram calculados os totais mensais e anuais de chuva utilizando planilhas estatísticas do Microsoft Excel. Os dados das séries anuais receberam o seguinte tratamento: cálculo da média
(X) e do Desvio Padrão (DP) da série, identificação dos anos mais chuvosos (P.anual $\geq \mathrm{X}+\mathrm{DP}$ ) e mais secos (P.anual $\leq \mathrm{X}+\mathrm{DP}$ ), cálculo da média móvel (com base 3) e cálculo da linha de tendência (por regressão linear simples).

A análise diária das precipitações envolveu o cálculo da participação de cada classe de intensidade no período total em comparação com os anos extremos. As quatro classes podem ser visualizadas na TABELA 1:

TABELA 1: Classes de intensidade.

\begin{tabular}{c|c|l}
\hline Classes & Milímetros de Chuva & \multicolumn{1}{c}{ Caracterização } \\
\hline 1 & $2-10$ & $\begin{array}{l}\text { Segundo Miranda (1992) e Figueiró (2005) são } \\
\text { caracterizadas como os menores índices, sendo } \\
\text { praticamente toda interceptada e armazenada pela } \\
\text { vegetação e devolvida à atmosfera por evaporação. }\end{array}$ \\
\hline 2 & $10,1-50$ & $\begin{array}{l}\text { São caracterizadas como intermediárias, sendo } \\
\text { responsáveis pela recarga dos mananciais a partir da } \\
\text { água de infiltração (FIGUEIRÓ, 2005). }\end{array}$ \\
\hline 3 & $50,1-100$ & $\begin{array}{l}\text { Representando os eventos de baixa frequência e alta } \\
\text { intensidade, potencializa-dores de desastres naturais } \\
\text { (DEHN e BUMA, 1999) e que pouco contribuem } \\
\text { para a manutenção da estabilidade hidrológica do } \\
\text { geoecossistema, uma vez que o volume de água } \\
\text { produzido é rapidamente perdido pelo sistema na } \\
\text { forma de escoamento superficial e subsuperficial } \\
\text { (FIGUEIRÓ, 2005). }\end{array}$ \\
\hline
\end{tabular}

Os cartogramas foram confeccionados conforme a distribuição espacial das enchentes, por município, que margeiam o rio Uruguai, no estado do Rio Grande do Sul. Assim, nos cartogramas é possível visualizar os municípios atingidos pelas enchentes nos 26 anos analisados.
Para a confecção dos cartogramas, com a representação das enchentes ocorridas, foi utilizado o software Spring 5.0 e o produto final trabalhado no CorelDRAW 12.

A seguir, é apresentado um diagrama com as principais etapas desenvolvidas no decorrer deste trabalho (FIGURA 4). 
Enchentes do Rio Uruguai no Rio Grande do Sul entre 1980 e 2005: uma análise geográfica Eléia Righi, Luis Eduardo de Souza Robaina

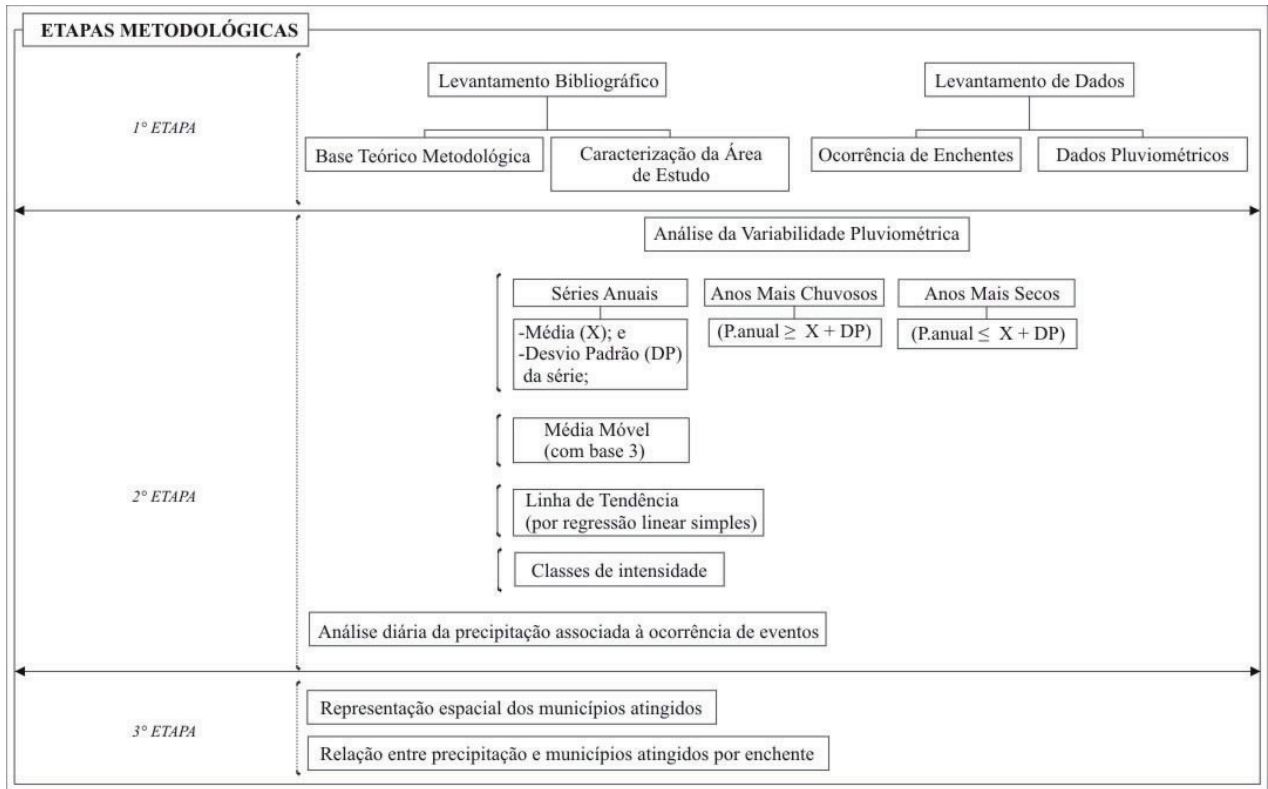

FIGURA 4: Diagrama com as principais etapas desenvolvidas no decorrer do trabalho.

\section{RESULTADOS E DISCUSSÕES:}

4.1. Análise da Variabilidade Pluviométrica de Frequência e Intensidade de Chuvas:

A análise dos dados pluviométricos diários permitiu perceber que há uma significativa diferença na distribuição das chuvas segundo as classes de intensidade.

Nas estações de Erechim (FIGURA 5), São Borja (FIGURA 6) e Santa Rosa (FIGURA 7) percebe-se que as chuvas em todas as classes vêm apresentando uma tendência de equilíbrio dinâmico, sem nenhuma indicação significativa de aumento.

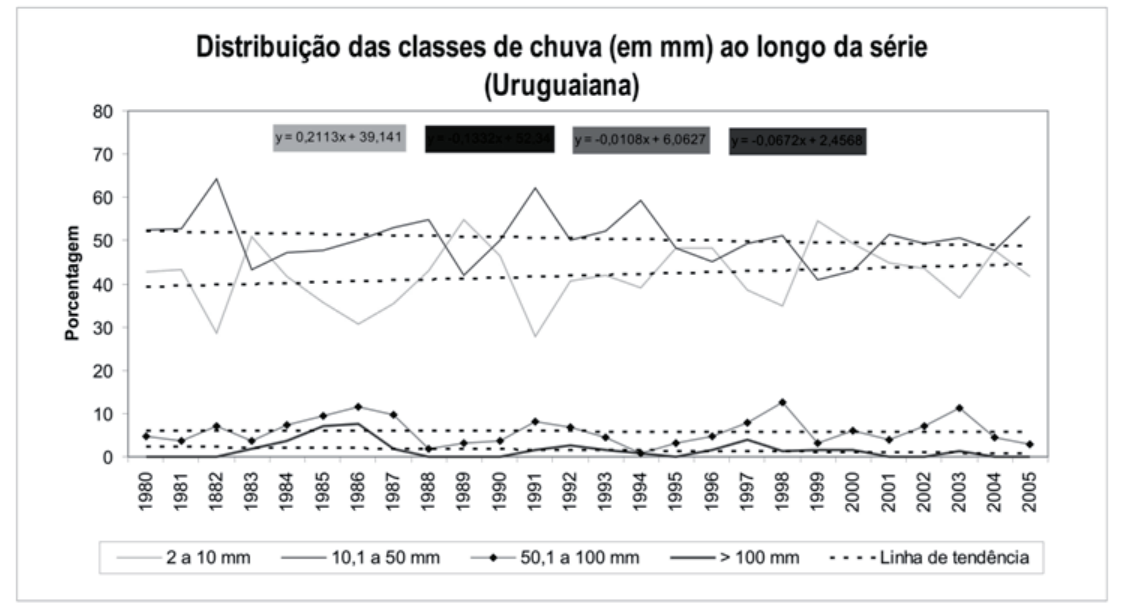

FIGURA 5: Gráfico da frequência anual dos eventos pluviométricos (em \%) por classe de intensidade, para a Estação pluviométrica de Erechim. 
Enchentes do Rio Uruguai no Rio Grande do Sul entre 1980 e 2005: uma análise geográfica Eléia Righi, Luis Eduardo de Souza Robaina

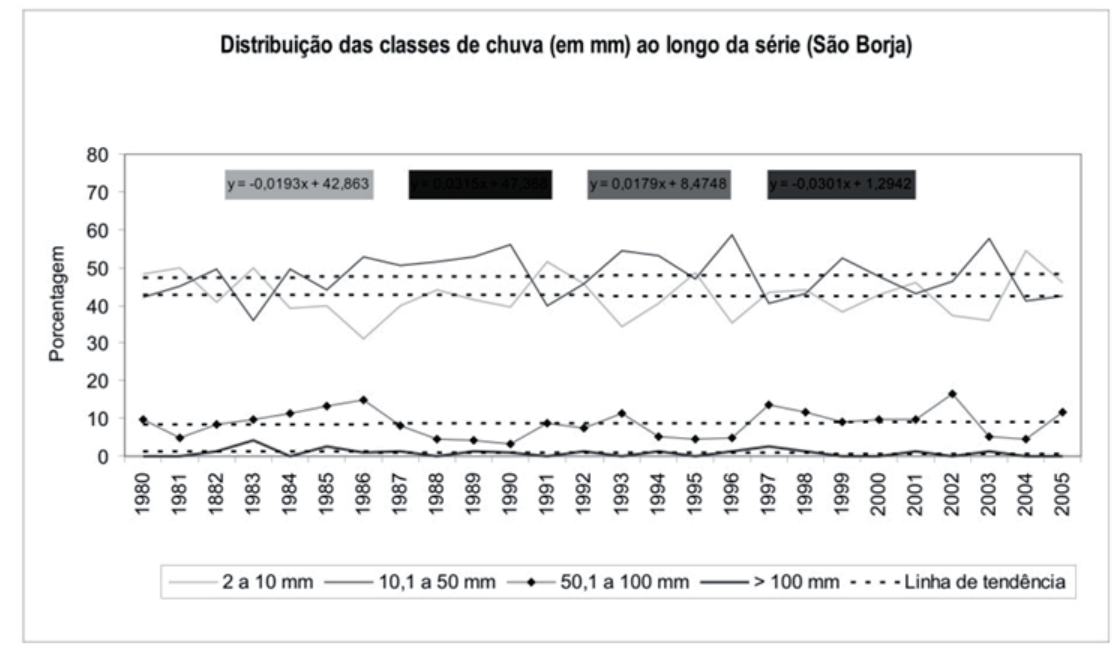

FIGURA 6: Gráfico da frequência anual dos eventos pluviométricos (em \%) por classe de intensidade, para a Estação pluviométrica de São Borja.

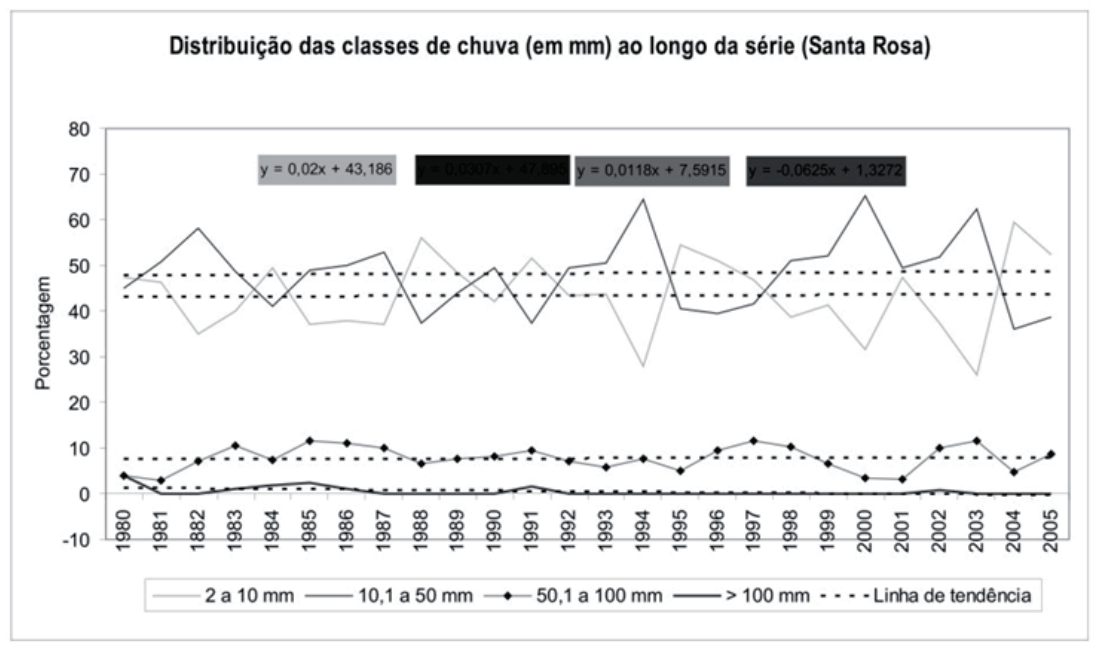

FIGURA 7: Gráfico da frequência anual dos eventos pluviométricos (em \%) por classe de intensidade, para a Estação pluviométrica de Santa Rosa.

Dessa forma a intensidade dos eventos das classes 3 e 4, não indicam pelos dados analisados, nenhuma tendência de aumento da frequência de desastres naturais associados às chuvas; ao mesmo tempo a grande participação dos eventos de classe 1 e 2 demonstram uma tendência de manutenção da estabilidade do conjunto solo-vegetação no que se refere à alimentação hidrológica.

Já as Estações de Ijuí (FIGURA 8) e Quaraí
(FIGURA 9) possuem uma indicação de $-0,12$ na reta de tendência e Quaraí de - 0,14 , o que indica uma leve tendência (embora estatisticamente não significativa) à diminuição das chuvas de menor intensidade.

A tendência da classe 2 aparece nas duas estações com uma inclinação positiva, o que é muito satisfatório para todo o sistema, uma vez que são estas as chuvas que representam o maior potencial de manutenção do equilíbrio hidrológico da paisagem. 


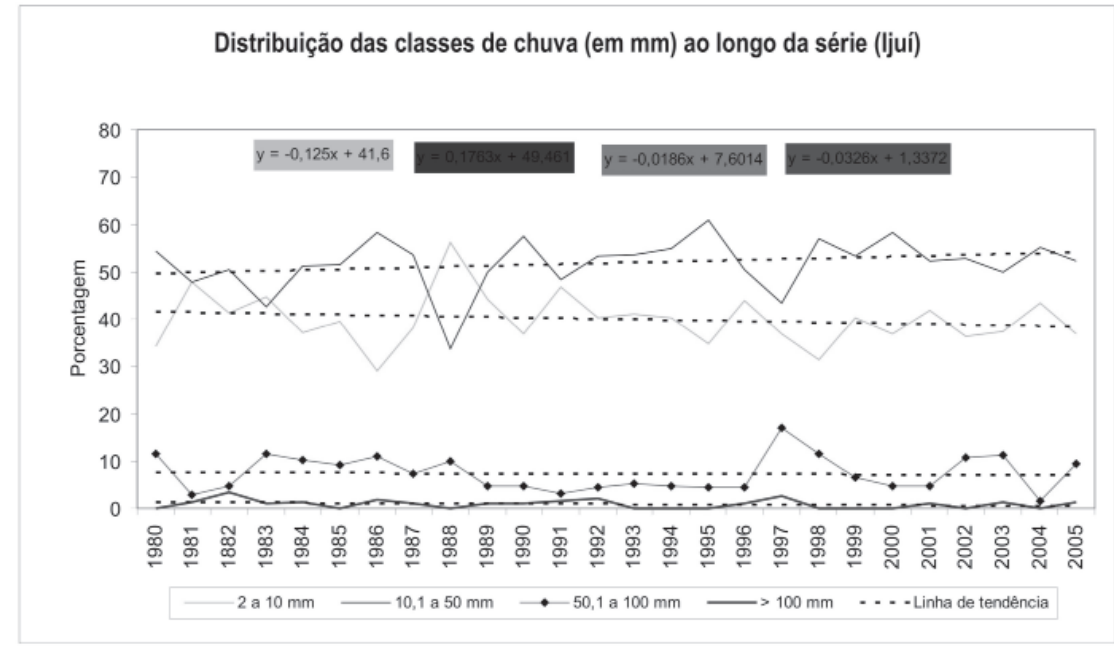

FIGURA 8: Gráfico da frequência anual dos eventos pluviométricos (em \%) por classe de intensidade, para a Estação pluviométrica de Ijuí.

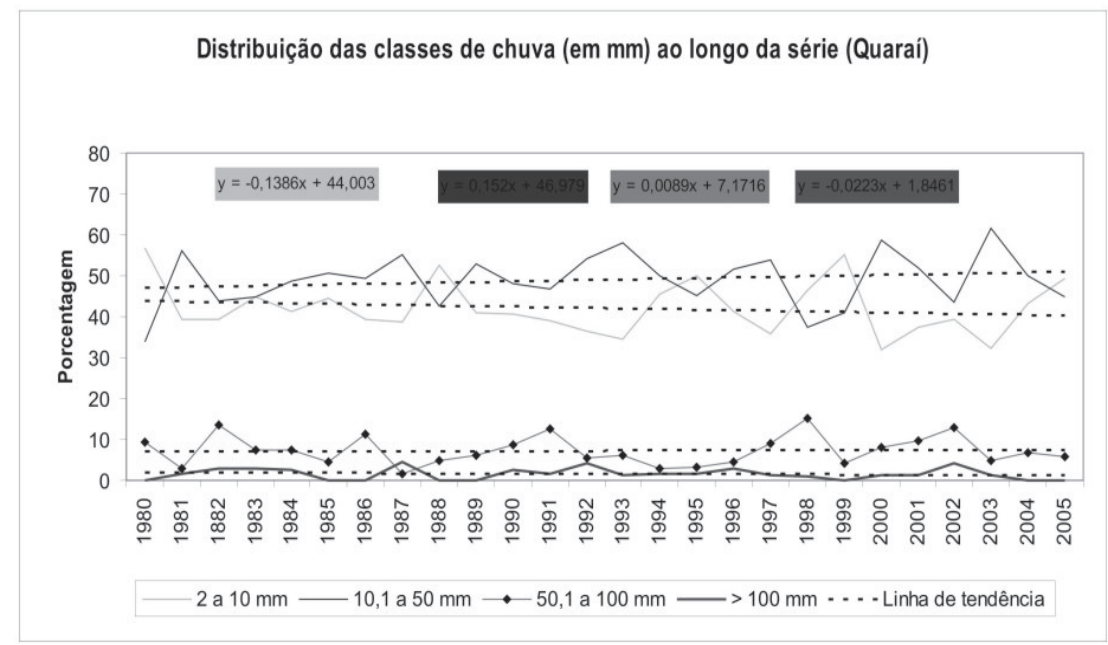

FIGURA 9: Gráfico da frequência anual dos eventos pluviométricos (em \%) por classe de intensidade, para a Estação pluviométrica de Quaraí.

A estação de Uruguaiana (FIGURA 10) apresenta uma leve tendência de redução na classe 2 e uma leve tendência de aumento da classe 1, tendências que não comprometem negativamente 0 sistema, uma vez que não se verifica uma substituição das chuvas menores pelas de maior intensidade. 
Enchentes do Rio Uruguai no Rio Grande do Sul entre 1980 e 2005: uma análise geográfica Eléia Righi, Luis Eduardo de Souza Robaina

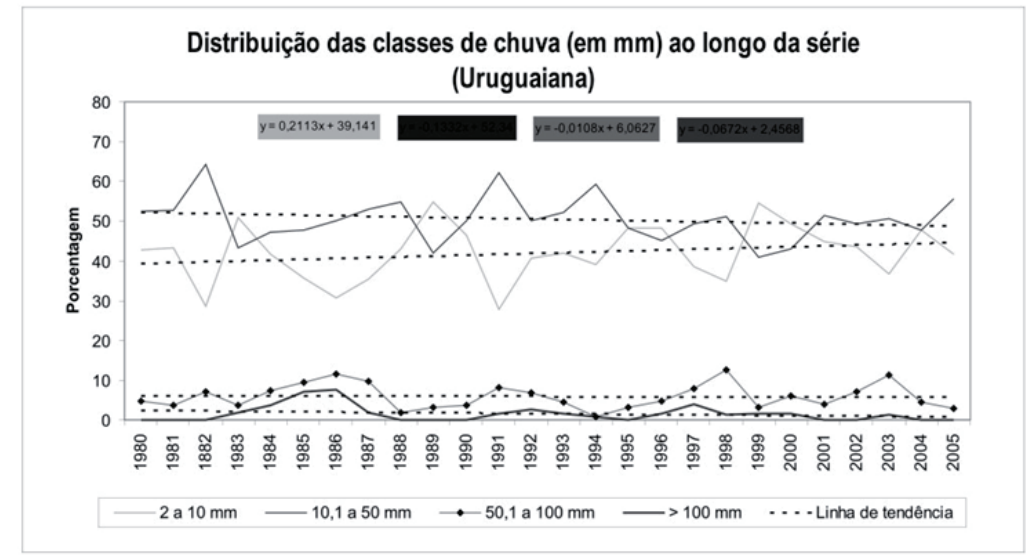

FIGURA 10: Gráfico da frequência anual dos eventos pluviométricos (em \%) por classe de intensidade, para a Estação pluviométrica de Uruguaiana.

Identificadas as tendências de comportamento de cada uma das classes, partiu-se para a análise da participação de cada uma delas na produção dos anos extremos (secos e chuvosos - conforme FIGURA 11).

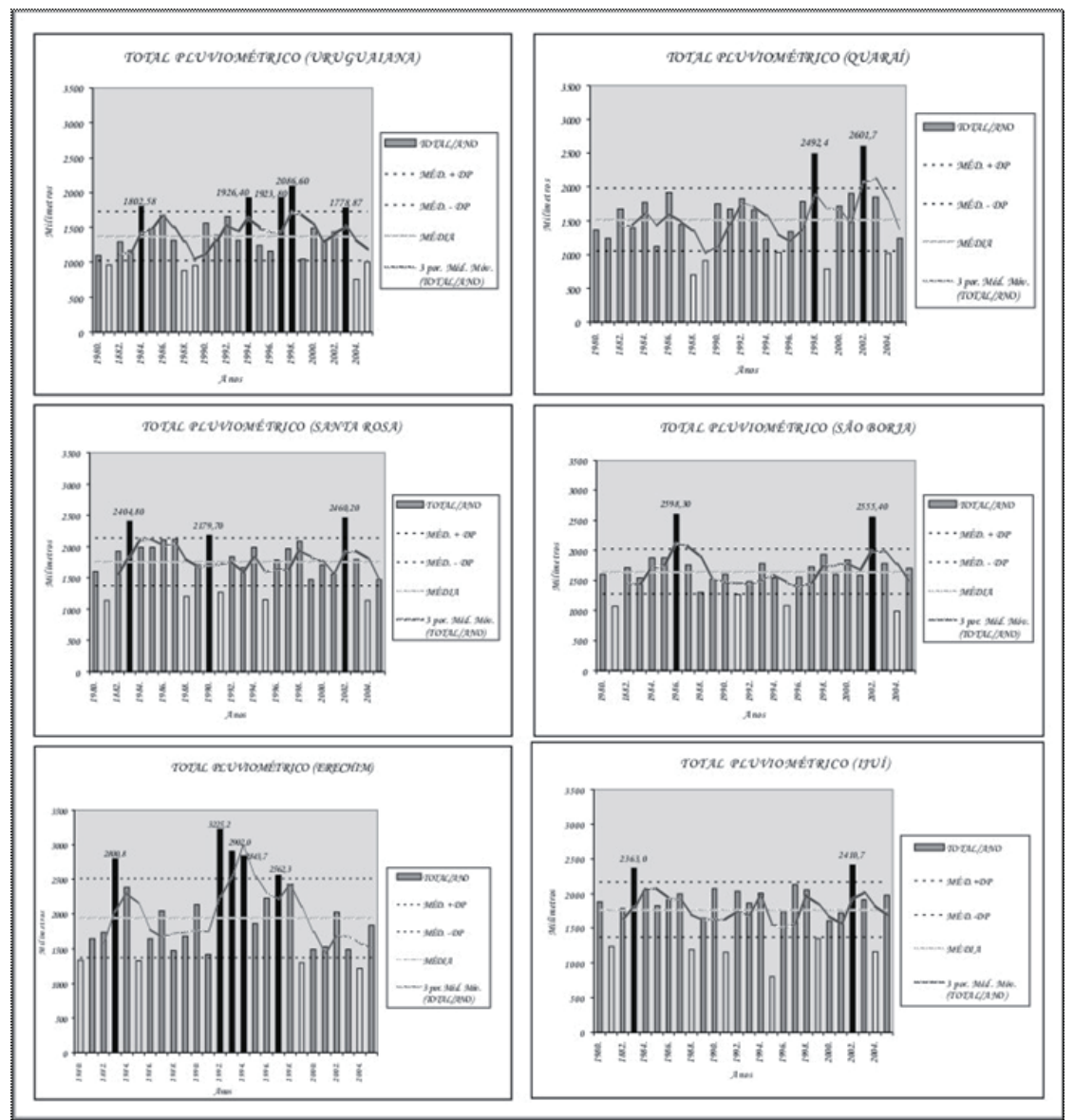

FIGURA 11: Distribuição da precipitação anual da série histórica das seis Estações selecionadas.

As barras pretas indicam os anos chuvosos acima do desvio padrão positivo, cinza escuro indicam os anos mais chuvosos e as barras mais claras, os anos mais secos.

Sociedade \& Natureza, Uberlândia, 22 (1): 35-54, abr. 2010 
Três Estações (São Borja, Ijuí e Quaraí) apresentaram apenas dois anos de excepcionalidade positiva dentre os vinte e cinco anos analisados na série. A análise destes anos chuvosos, nas três estações, permitiu concluir que a única classe que apresenta comportamento homogêneo (crescimento em relação à média dos anos normais) foi à classe 3 .

As Estações de Uruguaiana, Erechim e Santa Rosa possuem o maior numero de desvios positivos, mas também como as outras estações os maiores índices de intensidade da classe 3 estão relacionados a esses desvios.

Esse resultado torna-se relevante, pois as chuvas de classe 3 (50,1 a $100 \mathrm{~mm})$ são as maiores causadoras de enchentes, como será comprovado nas análises diárias.

Cabe destacar ainda, que para todas as seis Estações, os anos com excepcionalidade negativa, possuem os menores eventos de precipitação da classe 3 .

As outras classes de intensidade de todas as Estações em relação aos anos secos, chuvosos e normais, apresentam diferentes oscilações, não permitindo uma relação significativa entre evento e excepcionalidade/normalidade.

\subsection{Da Relação: Enchente versus Fenômeno El Niño}

A análise dos eventos de enchentes e sua correlação com os índices pluviométricos permitem estabelecer uma discussão sobre o papel do fenômeno ENOS - El Niño.

Sabe-se que o fenômeno El Niño não possui atuação durante todo o decorrer de um ano, mas sim, em alguns meses, que comumente não são os mesmos meses a cada manifestação do fenômeno.

De acordo com a TABELA 2, verificamos os valores IOS (o IOS é calculado a partir da diferença de pressão atmosférica ao nível do mar existente entre a Ilha do Tahiti, no setor oeste do Oceano Pacífico e as Ilhas Darwin, no setor leste do Pacífico. Quanto maior for esta diferença, em valores negativos, maior a intensidade do fenômeno El Niño durante o mês registrado) para os anos de ocorrência do El Niño.

Os valores mais extremos (entre -10,0 e -35,0) foram considerados como os de máxima atividade e intensidade mensal registrada para o El Niño.

TABELA 2: Índice de Oscilação Sul (IOS) mensal nas ocorrências de evento El Niño.

\begin{tabular}{c|c|c|c|c|c|c|c|c|c|c|c|c}
\hline Ano & Jan & Fev & Mar & Abr & Maio & Jun & Jul & Ago & Set & Out & Nov & Dez \\
\hline 1982 & 9,4 & 0,6 & 2,4 & $-3,8$ & $-8,2$ & $-20,1$ & $-19,3$ & $-23,6$ & $-21,4$ & $-20,2$ & $-31,1$ & $-21,3$ \\
\hline 1983 & $-30,6$ & $-33,3$ & $-28,0$ & $-17,0$ & 6,0 & $-3,1$ & $-7,6$ & 0,1 & 9,9 & 4,2 & $-0,7$ & 0,1 \\
\hline 1986 & 8,0 & $-10,7$ & 0,8 & 1,2 & $-6,6$ & 10,7 & 2,2 & $-7,6$ & $-5,2$ & 6,1 & $-13,9$ & $-13,6$ \\
\hline 1987 & $-6,3$ & $-12,6$ & $-16,6$ & $-24,4$ & $-21,6$ & $-20,1$ & $-18,6$ & $-14,0$ & $-11,2$ & $-5,6$ & $-1,4$ & $-4,5$ \\
\hline 1988 & $-1,1$ & $-5,0$ & 2,4 & $-1,3$ & 10,0 & $-3,9$ & 11,3 & 14,9 & 20,1 & 14,6 & 21,0 & 10,8 \\
\hline 1990 & $-1,1$ & $-17,3$ & $-8,5$ & $-0,5$ & 13,1 & 1,0 & 5,5 & $-5,0$ & $-7,6$ & 1,8 & $-5,3$ & $-2,4$ \\
\hline 1991 & 5,1 & 0,6 & $-10,6$ & $-12,9$ & $-19,3$ & $-5,5$ & $-1,7$ & $-7,6$ & $-16,6$ & $-12,9$ & $-7,3$ & $-16,7$ \\
\hline 1992 & $-25,4$ & $-9,3$ & $-24,2$ & $-18,7$ & 0,5 & $-12,8$ & $-6,9$ & 1,4 & 0,8 & $-17,2$ & $-7,3$ & $-5,5$ \\
\hline 1993 & $-8,2$ & $-7,9$ & $-8,5$ & $-21,1$ & $-8,2$ & $-16,0$ & $-10,8$ & $-14,0$ & $-7,6$ & $-13,5$ & 0,6 & 1,6 \\
\hline 1994 & $-1,6$ & 0,6 & $-10,6$ & $-22,8$ & $-13,0$ & $-10,4$ & $-18,0$ & $-17,2$ & $-17,2$ & $-14,1$ & $-7,3$ & $-11,6$ \\
\hline 1995 & $-4,0$ & $-2,7$ & 3,5 & $-16,6$ & $-9,0$ & $-1,5$ & 4,2 & 0,8 & 3,2 & $-1,3$ & 1,3 & $-5,5$ \\
\hline 1997 & 4,1 & 13,3 & $-8,5$ & $-16,2$ & $-22,4$ & $-24,1$ & $-9,5$ & $-19,8$ & $-14,8$ & $-17,8$ & $-15,2$ & $-9,1$ \\
\hline 1998 & $-23,5$ & $-19,2$ & $-28,5$ & $-24,4$ & 0,5 & 9,9 & 14,6 & 9,8 & 11,1 & 10,9 & 12,5 & 13,3 \\
\hline 2002 & 2,7 & 7,7 & $-5,2$ & $-3,8$ & $-14,5$ & $-6,3$ & $-7,6$ & $-14,6$ & $-7,6$ & $-7,4$ & $-6,0$ & $-10,6$ \\
\hline 2003 & $-2,0$ & $-7,4$ & $-6,8$ & $-5,5$ & $-7,4$ & $-12,0$ & 2,9 & $-1,8$ & $-2,2$ & $-1,9$ & $-3,4$ & 9,8 \\
\hline 2004 & $-11,6$ & 8,6 & 0,2 & $-15,4$ & 13,1 & $-14,4$ & $-6,9$ & $-7,6$ & $-2,8$ & $-3,7$ & $-9,3$ & $-8,0$ \\
\hline 2005 & 1,8 & $-29,1$ & 0,2 & $-11,2$ & $-14,5$ & 2,6 & 0,9 & $-6,9$ & 3,9 & 10,9 & $-2,7$ & 0,6 \\
\hline
\end{tabular}

Fonte: NOAA/CPC. Disponível em: <http://www.cpc.noaa.gov/>. 
Enchentes do Rio Uruguai no Rio Grande do Sul entre 1980 e 2005: uma análise geográfica Eléia Righi, Luis Eduardo de Souza Robaina

Ao relacionarmos os valores de IOS com as enchentes (TABELA 3 - próxima), destaca-se que 25 eventos ocorreram com IOS negativo, permitindo concluir que as excepcionalidades pluviométricas que levaram a ocorrer tais desastres podem ter ligação direta com o fenômeno.

\subsection{Análise Diária da Precipitação das 10 Estações Meteorológicas versus Inundações}

$\mathrm{Na}$ série analisada foram observadas 41 ocorrências de inundações (TABELA 3), sendo que, em alguns anos foi registrado mais de um evento.

TABELA 3: Relação entre o ano, o mês e os dias da ocorrência de enchente.

\begin{tabular}{|c|c|c|c|}
\hline Ano & Mês & $\begin{array}{l}\text { Dias Analisados com } \\
\text { Precipitação Registrada }\end{array}$ & Municípios Atingidos \\
\hline 1980 & Outubro & 17 a 29 & São Borja \\
\hline 1982 & Julho & 02 a 12 & São Borja e Uruguaiana \\
\hline 1982 & Novembro & 01 a 12 & Uruguaiana e Itaqui \\
\hline 1983 & Maio & 01 a 11 & Itaqui, Porto Lucena, Porto Xavier, São Borja e Uruguaiana \\
\hline 1983 & Junho & 20 a 24 & São Borja \\
\hline 1983 & Julho & 01 a 16 & $\begin{array}{c}\text { Alecrim, Alpestre, Aratiba, Caiçara, Crissiumal, Iraí, Itaqui, Machadinho, } \\
\text { Marcelino Ramos, Mariano Moro, Maximiliano de Almeida, Nonoai, } \\
\text { Porto Lucena, Porto Xavier, Roque Gonzales, São Borja, São Nicolau, } \\
\text { Uruguaiana, Vicente Dutra }\end{array}$ \\
\hline 1984 & Junho & 01 a 06 & São Borja \\
\hline 1984 & Agosto & 31/Jul a 09 & $\begin{array}{c}\text { Aratiba, Crissiumal, Iraí, Itaqui, Marcelino Ramos, Maximiliano de } \\
\text { Almeida, Nonoai, Porto Lucena, Porto Xavier, São Borja, Três Passos, } \\
\text { Uruguaiana, Vicente Dutra }\end{array}$ \\
\hline 1984 & Outubro & 02 a 09 & São Borja, Itaqui e Uruguaiana \\
\hline 1986 & Abril & 01 a 09 & São Borja, Itaqui e Uruguaiana \\
\hline 1987 & Abril & 09 a 19 & São Borja, Itaqui e Uruguaiana \\
\hline 1987 & Maio & 06 a 15 & São Borja, Porto Lucena e Porto Xavier \\
\hline 1987 & Julho & 27 a 30 & São Borja \\
\hline 1987 & Agosto & 28 a 31 & Uruguaiana \\
\hline 1988 & Setembro & 20 a 23 & Alpestre, Irai e Nonoai \\
\hline 1989 & Setembro & 08 a 13 & São Borja, Itaqui, Uruguaiana, Porto Xavier, Porto Lucena e Iraí \\
\hline 1990 & Abril & 01 a 07 & São Borja \\
\hline 1990 & Maio & 27 a 31 & $\begin{array}{l}\text { Aratiba, Iraí, Machadinho, Marcelino Ramos, Maximiliano de Almeida, } \\
\text { Nonoai, Porto Lucena, Porto Xavier, São Borja, São Nicolau, Três Passos }\end{array}$ \\
\hline 1990 & Junho & 01 a 06 & Uruguaiana e Itaqui \\
\hline 1990 & Setembro & 17 a 22 & São Borja \\
\hline 1990 & Outubro & 05 a 14 & $\begin{array}{l}\text { Alpestre, Iraí, Itaqui, Marcelino Ramos, Mariano Moro, São Borja, São } \\
\text { Nicolau }\end{array}$ \\
\hline 1990 & Novembro & 03 a 12 & São Borja \\
\hline 1991 & Abril & 23 a 26 & Alpestre \\
\hline 1992 & Maio & 21 a 28 & São Borja, Itaqui, Uruguaiana, Porto Xavier e Porto Lucena \\
\hline 1992 & Julho & 28/Jun a 06 & Iraí, Porto Lucena, Porto Xavier, São Borja e Vicente Dutra \\
\hline 1993 & Julho & 01 a 10 & $\begin{array}{c}\text { Barra do Guarita, Barracão, Dr. Maurício Cardoso, Iraí, Itaqui, } \\
\text { Machadinho, Marcelino Ramos, Maximiliano de Almeida, Porto Mauá, } \\
\text { Porto Vera Cruz, São Borja, Uruguaiana }\end{array}$ \\
\hline 1994 & Maio & 03 a 12 & São Borja \\
\hline 1994 & Julho & 01 a 08 & Caiçara, Itaqui, São Borja e Uruguaiana \\
\hline 1994 & Outubro & 13 a 20 & São Borja e Itaqui \\
\hline 1997 & Agosto & 01 a 07 & São Borja \\
\hline 1997 & Outubro & 07 a 16 & $\begin{array}{l}\text { Aratiba, Iraí, Itaqui, Itatiba do Sul, Marcelino Ramos, Mariano Moro, } \\
\text { Porto Mauá, Porto Xavier, São Borja, Uruguaiana, Vicente Dutra }\end{array}$ \\
\hline 1997 & Novembro & 28/Out a 07 & Barra do Quaraí, Garruchos, Crissiumal e Porto Mauá \\
\hline 1998 & Fevereiro & 01 a 11 & Itaqui, São Borja e Uruguaiana \\
\hline 1998 & Abril & 11 a 17 & Garruchos, Itaqui, Porto Xavier, São Borja e Uruguaiana \\
\hline 1998 & Agosto & 12 a 27 & Itaqui, São Borja e Uruguaiana \\
\hline 2000 & Outubro & 09 a 16 & Dr. Mauricio Cardoso, Porto Xavier e São Borja \\
\hline 2001 & Outubro & $27 /$ Set a 08 & Vicente Dutra \\
\hline 2002 & Outubro & 05 a 12 & Itaqui, São Borja e Uruguaiana \\
\hline 2003 & Dezembro & 11 a 17 & Itaqui e Uruguaiana \\
\hline 2005 & Maio & 14 a 21 & Barra do Guarita, São Borja, Itaqui e Uruguaiana \\
\hline 2005 & Junho & 11 a 17 & Itaqui, São Borja e Uruguaiana \\
\hline
\end{tabular}


Os anos que apresentaram um maior número de eventos registrados foram os anos de 1983, 1984, 1987, 1990, 1992, 1994, 1997, 1998 e 2005 (FIGURA 12). Estes podem ser relacionados com os anos caracterizados como chuvosos, pois somente os anos 1987 e 2005 não foram estatisticamente considerados chuvosos (acima da média e desvio padrão).

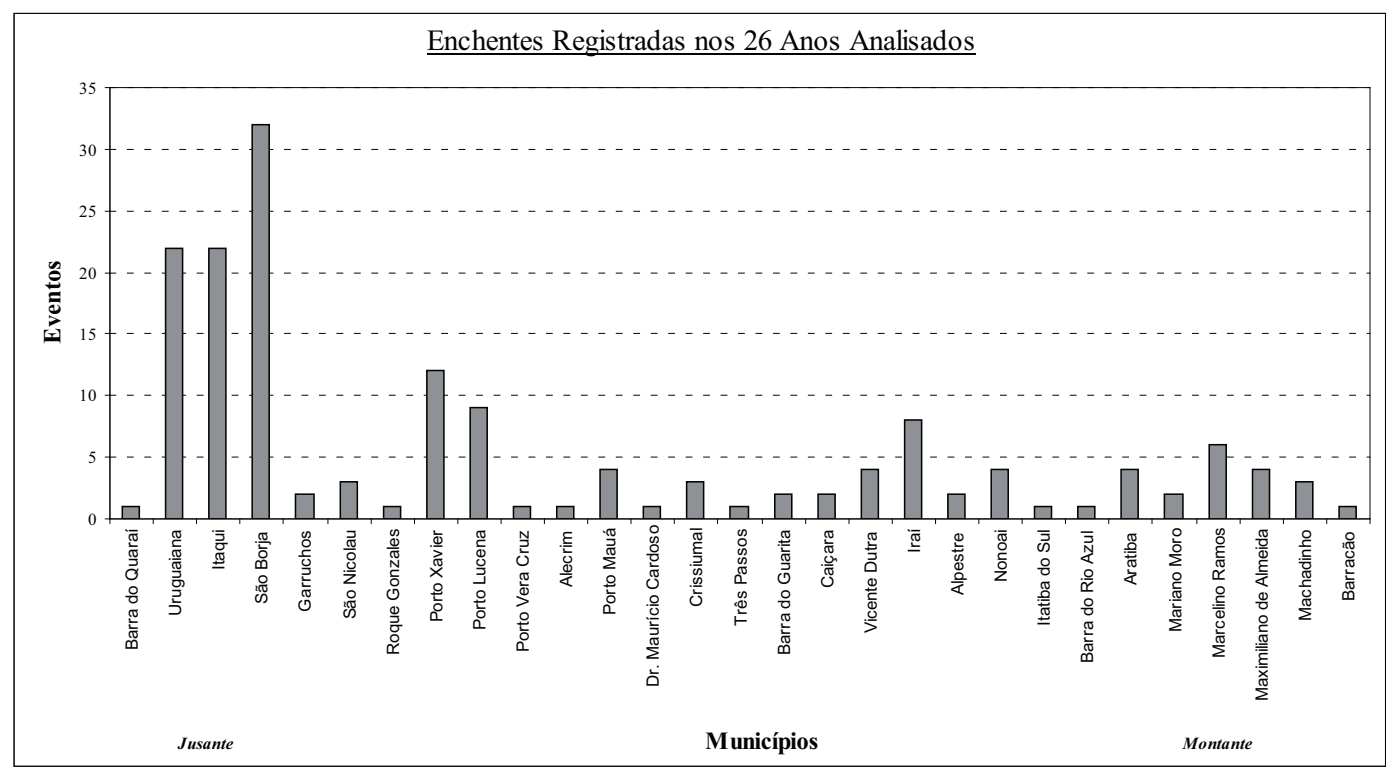

FIGURA 12: Gráfico dos municípios atingidos nos 25 anos analisados (apenas os municípios atingidos encontram-se no gráfico).

Muitas situações de emergência e calamidade pública foram registradas destacando os anos de 1983, 1984, 1989, 1990, 1993, 1997 e 1998.

\subsection{Análise dos Eventos (representativos)}

\subsubsection{Enchente de Julho / 1983}

Esta enchente atingiu vários municípios as margens do rio Uruguai (FIGURA 13) por chuvas ocorridas em toda a extensão da bacia hidrográfica, principalmente no alto curso entre os dias 04 e 14, e, de 04 a 08 no médio curso (estações de Santa Rosa, Porto Lucena e Ijuí). No baixo curso ocorreram chuvas somente entre os dias 14 e 15 que serviram para realimentar a situação de enchente.

Conforme os gráficos nas estações de Erechim, Palmitos e Palmeiras das Missões os índices ficam em torno de $100 \mathrm{~mm}$ entre os dias $04 \mathrm{e}$ 07 , as chuvas continuam ate o dia 16 , mas com níveis mais baixos.
Nas estações de Santa Rosa, Porto Lucena e Ijuí as maiores chuvas ocorrem entre os dias 04 e 08, máximo de $60 \mathrm{~mm}$, até o restante da análise os índices permanecem abaixo de $40 \mathrm{~mm}$. No restante das estações as chuvas são mínimas ocorrendo de forma esparsa.

Assim, mesmo que não ocorram chuvas a jusante, as precipitação em médio e alto curso do rio Uruguai de classe três, ocorridas por mais de um dia, são suficientes para que o evento atinja os municípios ali localizados.

Neste ano o evento El Niño foi considerado com intensidade forte, ocorrendo grandes excessos de precipitação pluvial em todo o Estado, mas a região noroeste foi a mais atingida, com excedentes pluviométricos iguais ou maiores do que $300 \mathrm{~mm}$, em algumas áreas, ocasionando grandes enchentes, especialmente no médio e baixo vale do rio Uruguai.

Salienta-se também, que as maiores chuvas 
Enchentes do Rio Uruguai no Rio Grande do Sul entre 1980 e 2005: uma análise geográfica

Eléia Righi, Luis Eduardo de Souza Robaina

ocorreram no Estado de Santa Catarina levando vários municípios a decretarem situação de calamidade pública. No Rio Grande do Sul os municípios atingidos que decretaram situação de emergência foram Aratiba, Caiçara, Crissiumal, Iraí, Itaqui,
Machadinho, Marcelino Ramos, Mariano Moro, Maximiliano de Almeida, Nonoai, Porto Lucena, Porto Xavier, São Borja, São Nicolau, Uruguaiana e Vicente Dutra.

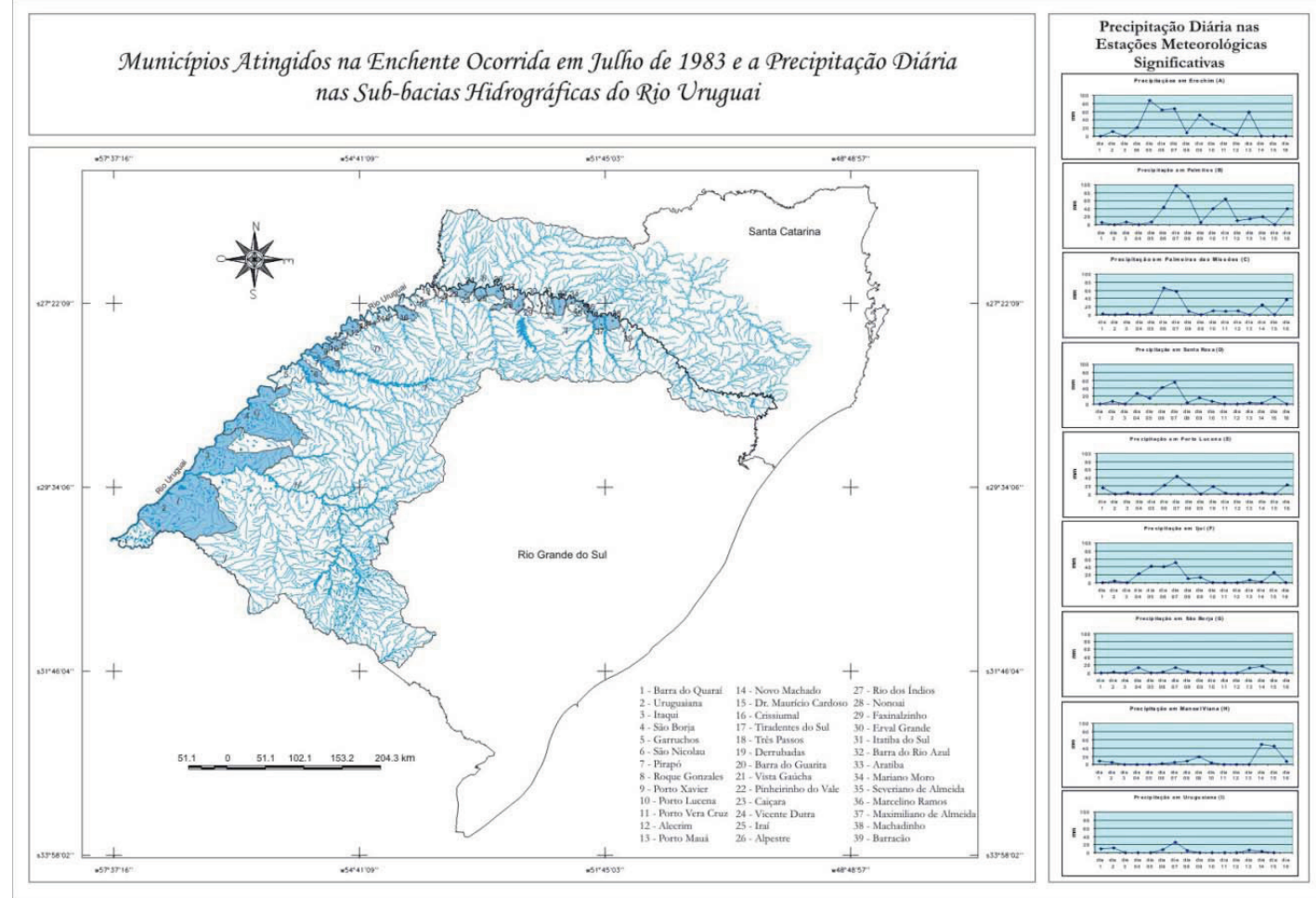

FIGURA 13: Mapa dos municípios atingidos e precipitação diária.

\subsubsection{Enchente de Agosto / 1984}

Foram atingidos municípios desde a montante até a jusante (FIGURA 14), Aratiba, Crissiumal, Iraí, Itaqui, Marcelino Ramos, Maximiliano de Almeida, Nonoai, Porto Lucena, Porto Xavier, São Borja, Três Passos, Uruguaiana e Vicente Dutra. As chuvas no médio e alto curso, com precipitações de classe 3 $(50,1-100 \mathrm{~mm})$ são as maiores influenciadoras para ocorrência da enchente.

Os maiores picos (classe 4) ocorrem na Estação meteorológica de Erechim, chegando a 120 $\mathrm{mm}$ no dia 05 . Somente entre os dias 04 e 07 choveu nesta estação o equivalente a $300 \mathrm{~mm}$.

Nas Estações de Palmitos e Palmeira das Missões entre os dias 05 e 08 os índices ficaram em torno de $80 \mathrm{~mm}$. Nas demais Estações as chuvas foram mínimas e às vezes quase nulas.

Assim, como salientado anteriormente, mesmo que não ocorram chuvas a jusante, as precipitação em médio e alto curso do rio Uruguai de classe três, ocorridas por mais de um dia, são suficientes para que o evento atinja os municípios ali localizados. 


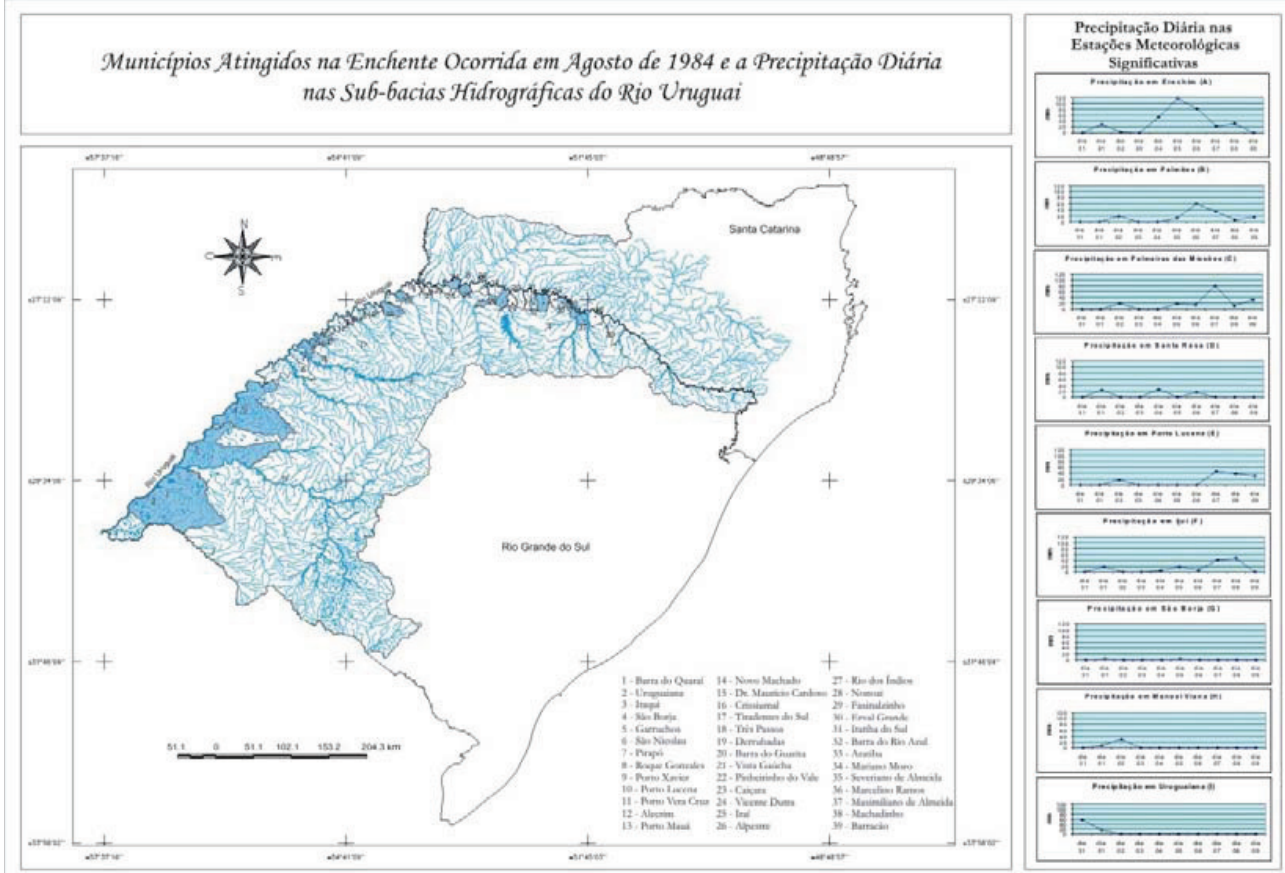

FIGURA 14: Mapa dos municípios atingidos e precipitação diária.

4.4.3. Enchente de Setembro / 1989

Nesta ocorrência de enchente foram atingidos os municípios de São Borja, Itaqui, Uruguaiana,
Porto Xavier, Porto Lucena e Irai (FIGURA 15), sendo decretada situação de emergência em todos, menos em Porto Lucena.

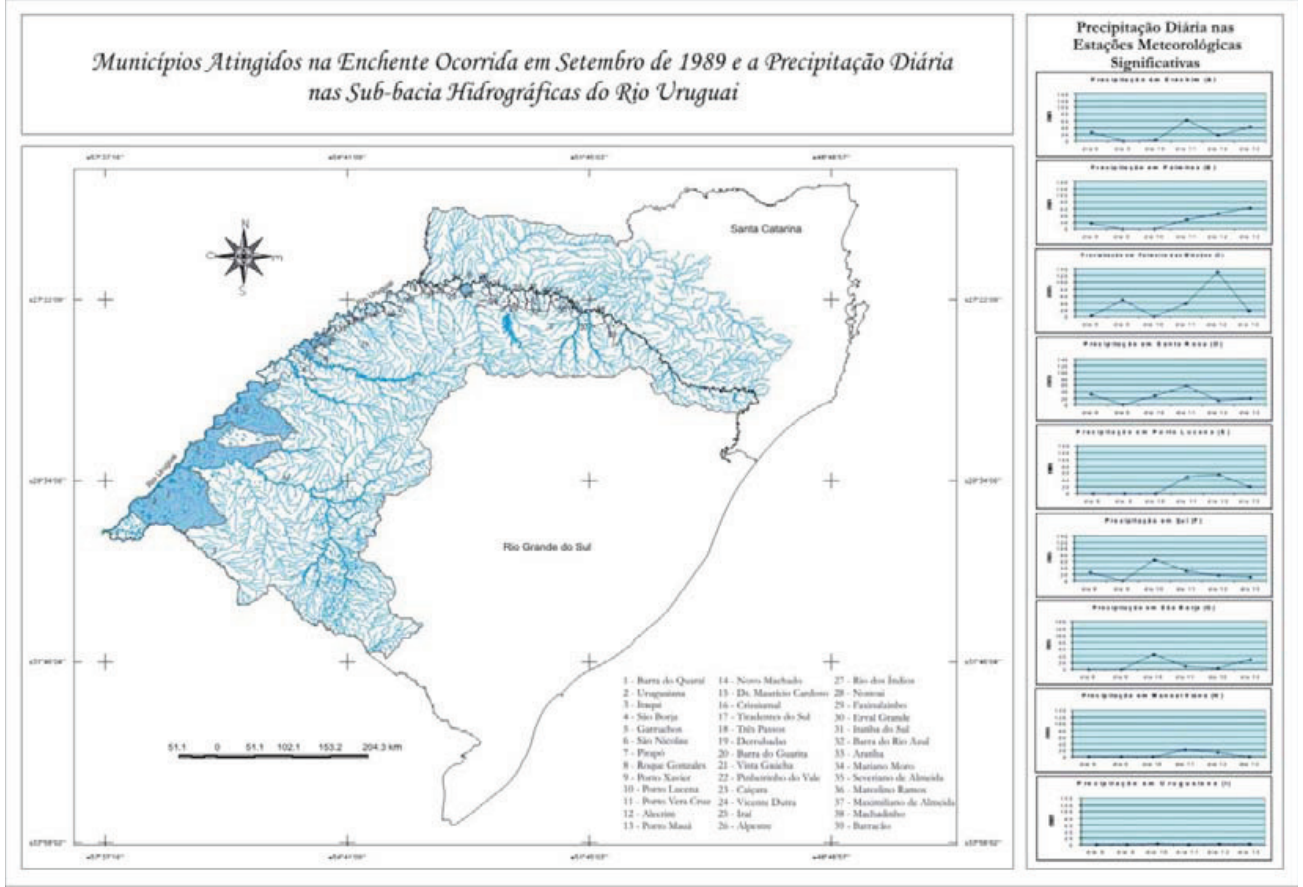

FIGURA 15: Mapa dos municípios atingidos e precipitação diária. 
Enchentes do Rio Uruguai no Rio Grande do Sul entre 1980 e 2005: uma análise geográfica Eléia Righi, Luis Eduardo de Souza Robaina

Observa-se que as Estações meteorológicas localizadas no médio e alto curso possuem registros de ocorrência de precipitações com altos índices. Nas Estações de Erechim, Palmitos e Palmeira das Missões as chuvas ocorrem de forma intensa chegando a chover no dia 12, $140 \mathrm{~mm}$ na Estação de Palmeira das Missões.

Em médio curso as chuvas ocorrem de forma mais moderada, possuindo índices em torno de 60 mm, ocorrida entre os dias 09 e 12 .

Os picos de chuvas ocorridos à jusante do rio são mínimos (máximo $20 \mathrm{~mm}$ ), não favorecendo a ocorrência da enchente, mas as precipitações que ocorrem à montante por um período maior, são essenciais para que esta enchente ocorra atingindo municípios em alto, médio e baixo curso do rio Uruguai.

\subsubsection{Enchente de Maio / 1990}

Em maio de 1990, 11 municípios atingidos decretaram situação de emergência (FIGURA 16). Nas Estações de Erechim, Palmeira das Missões e Santa Rosa choveram altos índices entre os dias 27 e 31.

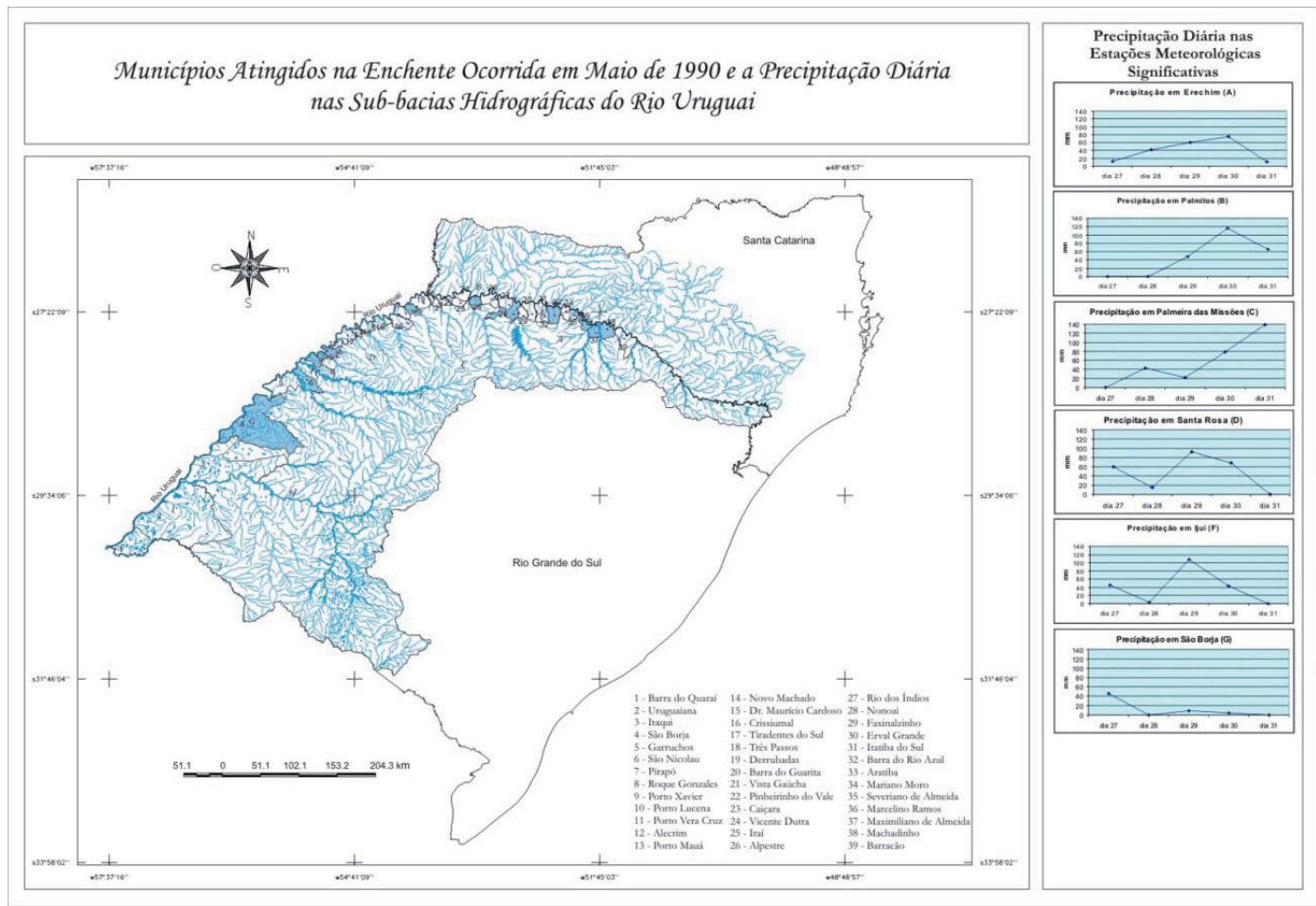

FIGURA 16: Mapa dos municípios atingidos e precipitação diária. 
A chuva registrada na Estação de Palmitos foi de $120 \mathrm{~mm}$ no dia 30 e Palmeira das Missões 140 mm no dia 31, em Ijuí as chuvas também chegam a $120 \mathrm{~mm}$ no dia 29, mas estes índices somente causam a enchente por estarem ocorrendo em conjunto com chuvas de classe 3 por mais de um dia, e sendo registradas em mais de uma Estação meteorológica.

\subsubsection{Enchente de Julho / 1993}

Nesta enchente 12 municípios foram atingidos, desde a montante até a jusante (FIGURA 17). Verifica-se que na Estação pluviométrica de Erechim ocorreram precipitações do dia 01 a 07 com elevados picos de classes 3 e 4 , sendo estas chuvas as responsáveis pelos municípios atingidos localizados no alto curso.

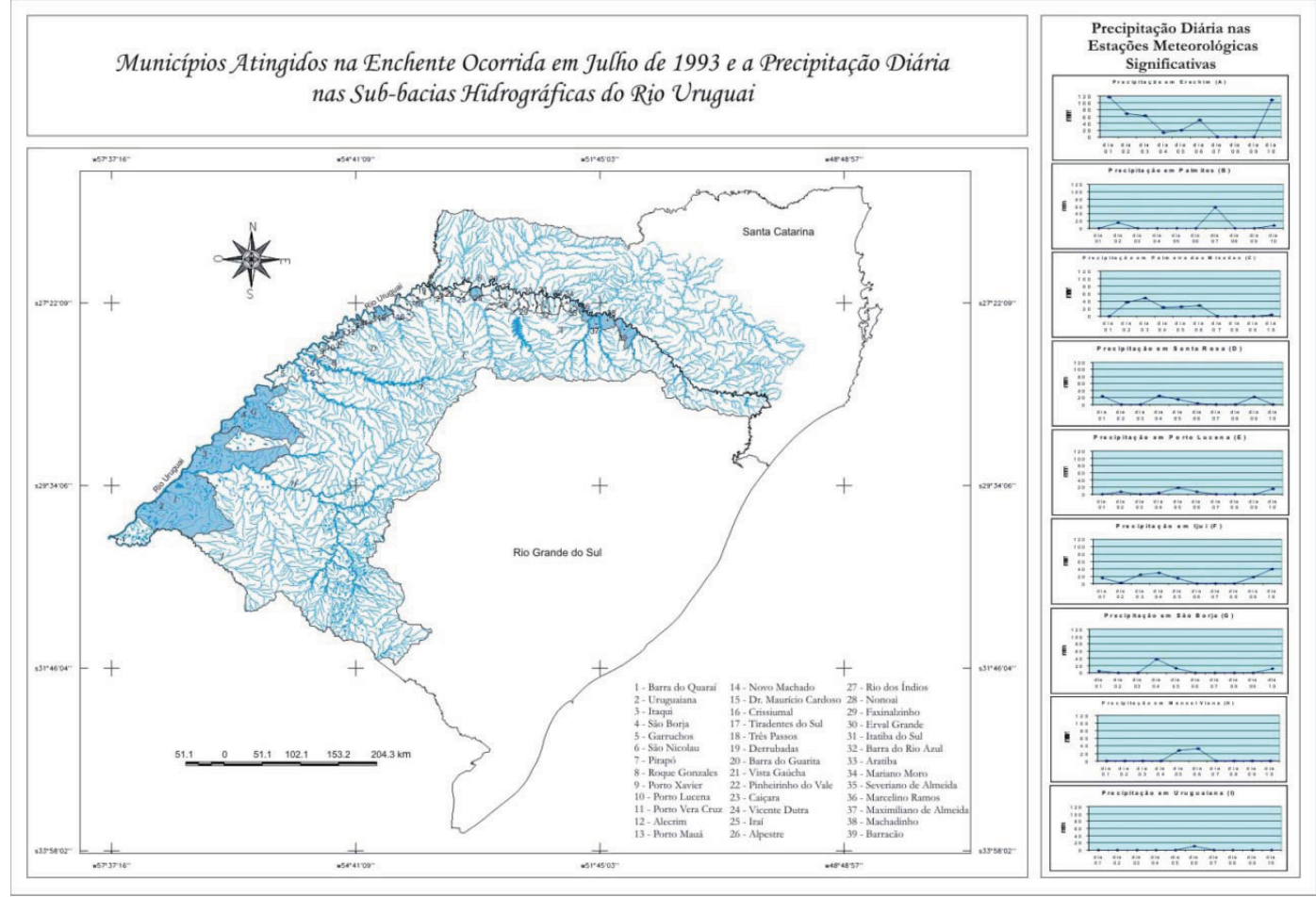

FIGURA 17: Mapa dos municípios atingidos e precipitação diária.

Nas outras Estações também houve registro de chuvas, porem com índices menores, que em conjunto com as chuvas a montante permitiu que vários municípios mais a jusante também decretassem situação de emergência. Neste mês verificou-se que ouve atuação do fenômeno El Niño com intensidade forte (IOS: - 10,8).

\subsubsection{Enchente de Outubro / 1997}

Em outubro de 1997, foram registrados picos de chuvas em todas as Estações meteorológicas, entre os dias 07 e 16 do mês, provocando ascensão das águas em toda a extensão do rio Uruguai e atingindo vários municípios (FIGURA 18). Dos municípios atingidos 9 decretam situação de emergência e 2 decretam situação de calamidade pública (Itaqui e Uruguaiana).

No alto curso as precipitações ocorrem por vários dias ficando em torno de 60 a $80 \mathrm{~mm}$ diários. Nas Estações em médio curso, Santa Rosa e Porto Lucena os picos de chuvas são maiores entre os dias 08 a 11 (em torno de $60 \mathrm{~mm} /$ dia).

Em baixo curso, principalmente em Uruguaiana ocorre um pico de chuva no dia 13 de 
Enchentes do Rio Uruguai no Rio Grande do Sul entre 1980 e 2005: uma análise geográfica

Eléia Righi, Luis Eduardo de Souza Robaina

quase $180 \mathrm{~mm}$, mas as chuvas que ocorreram neste dia e antes do mesmo nas Estações meteorológicas a médio e alto curso, são fundamentais para que este evento ocorra. Neste mês observa-se que o fenômeno
El Niño encontra-se agindo fortemente sobre todo o Brasil. Este evento deixou cerca de 9.000 pessoas desalojadas.

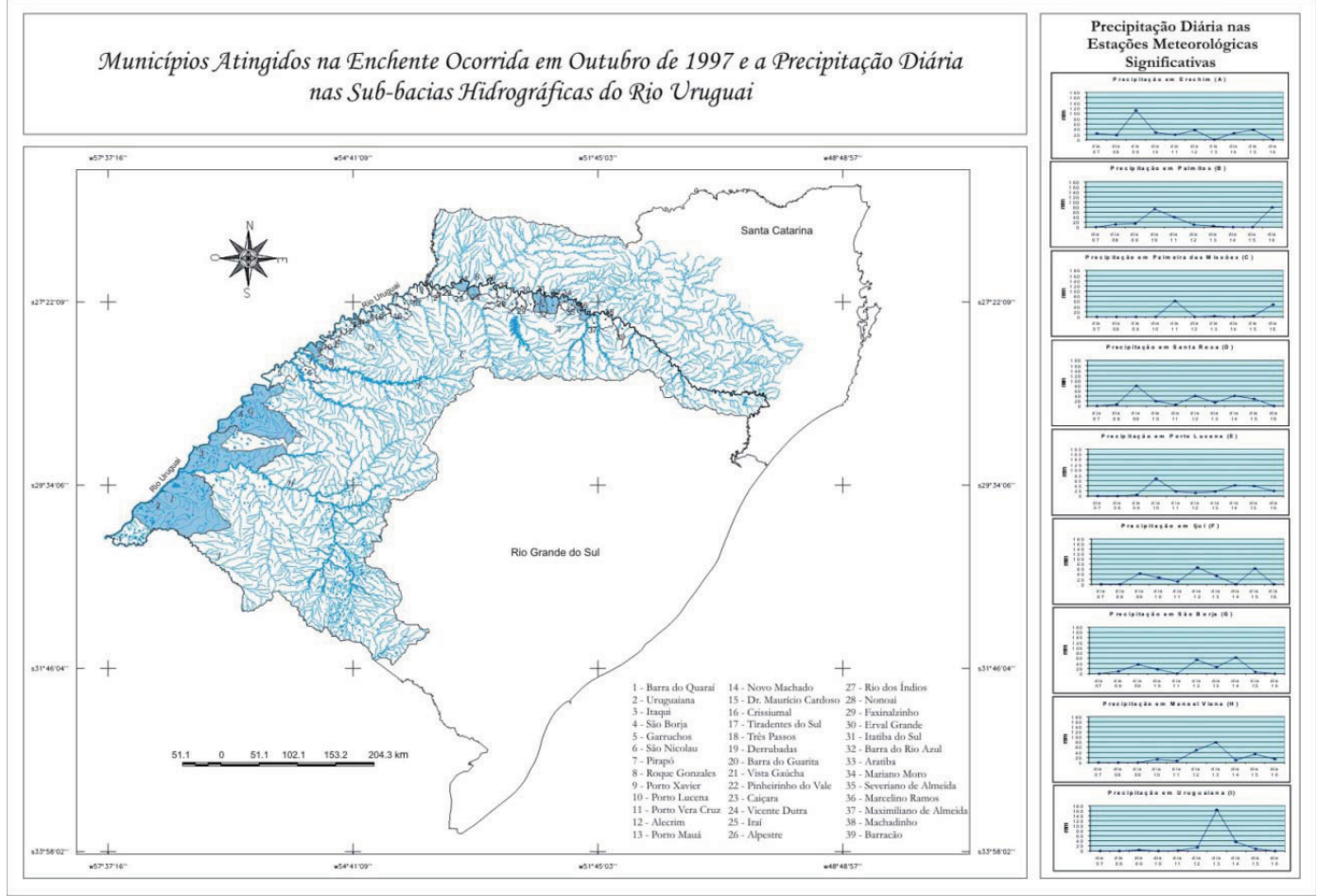

FIGURA 18: Mapa dos municípios atingidos e precipitação diária.

\subsubsection{Enchente de Abril / 1998}

Enchente atingindo vários municípios a médio e baixo curso, sendo que todos decretaram situação de emergência (FIGURA 19).

Em alto curso não foi registrado ocorrência de precipitações. As Estações de Porto Lucena e Santa Rosa não registraram altos índices de precipitação, mas foram suficientes para atingir os municípios em médio curso.

As chuvas mais significativas foram registradas em baixo curso (Estações meteorológicas de Manoel Viana e Uruguaiana), em Manoel Viana em apenas um único dia (12) choveu quase $160 \mathrm{~mm}$, nos dias 13 e 14 as chuvas ficaram em torno de 60 $\mathrm{mm}$. Em Uruguaiana as precipitações ocorreram entre os dias 12 e 15, ficando entre 60 a $80 \mathrm{~mm} /$ dia.

Os prejuízos causados por eventos de enchente nos municípios que margeiam o rio Uruguai no RS são muitos. Danos e destruição em lavouras, estradas e pontes estão entre os mais frequentes. Em muitas cidades centenas de moradias são submersas e centenas de pessoas são desabrigadas e flageladas e, em alguns casos, também são registradas vítimas fatais. 


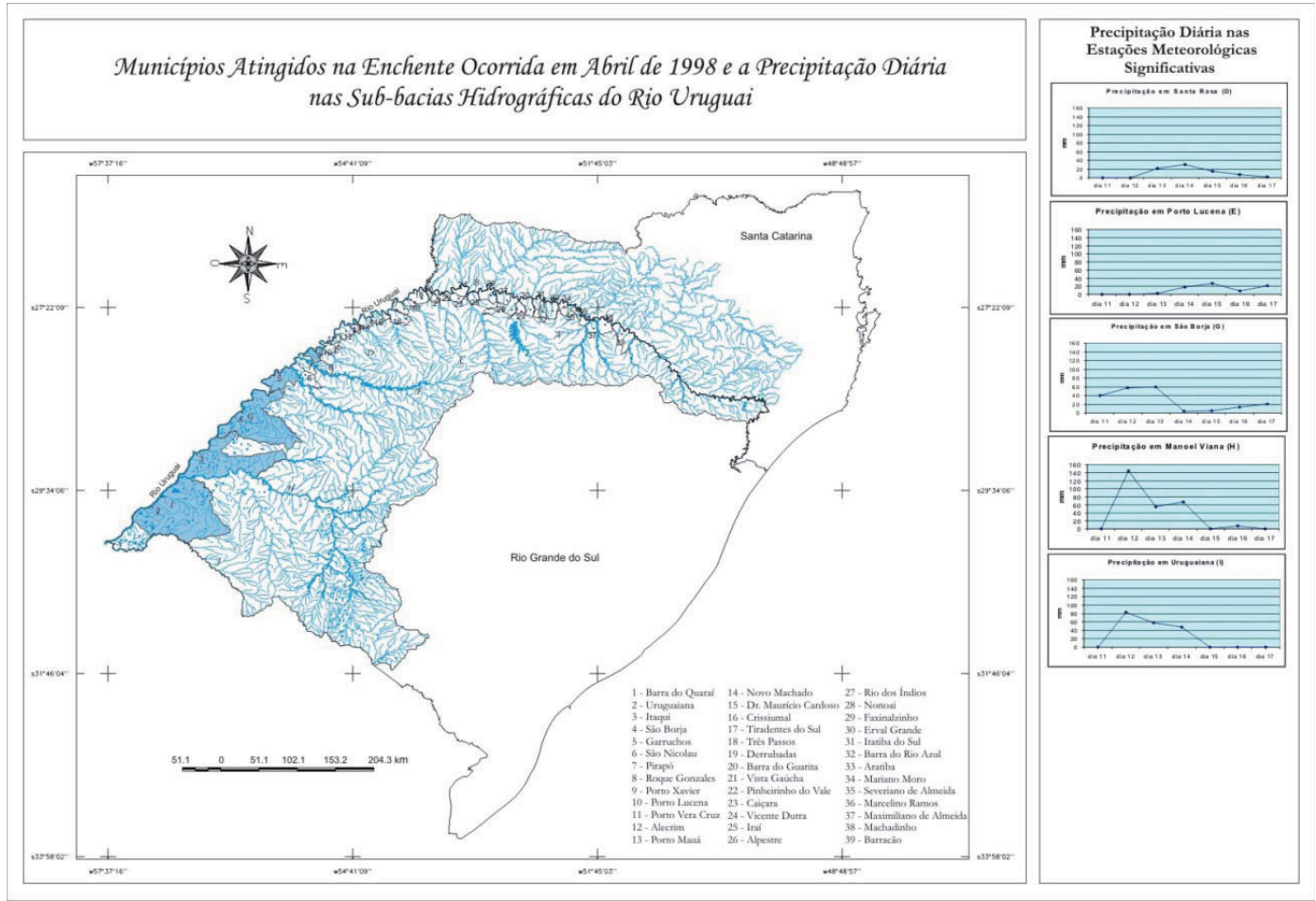

FIGURA 19: Mapa dos municípios atingidos e precipitação diária.

\section{CONSIDERAÇÕES FINAIS:}

Todos os rios têm sua área natural de inundação e esse fenômeno não é, necessariamente, sinônimo de catástrofe. Quando o homem ultrapassa os limites das condições naturais do meio em que vive, então as inundações passam a ser um problema social, econômico e/ou ambiental.

O rio Uruguai pode ser considerado um dos rios mais importantes para o estado do Rio Grande do Sul, possuindo sua população localizada mais às suas margens, tendo sido muito afetada por enchentes. Apesar dos avanços na mitigação e prevenção das enchentes, elas continuam causando um grande volume de danos, demonstrando as condições de risco às quais milhares de pessoas estão expostas.

Assim, ao relacionarmos a precipitação com os municípios atingidos, cartografando-os, busca-se contribuir com uma importante base para estudos mais avançados, que visem análises locais detalhadas de vulnerabilidade e de risco, como também uma fonte teórico-metodológica que possa motivar investigações futuras.

\section{REFERÊNCIAS}

ANA. Agência Nacional das Águas. Disponível em: $<$ www.ana.gov.br/>. Acesso em 04 ago. 2008.

BASSO, L. A. Bacias hidrográficas do Rio Grande do Sul: implicações ambientais. In: VERDUM, R.; BASSO, L. A.; SUERTEGARAY, D. M. A. (Org). Rio Grande do Sul: Paisagens e territórios em transformação. Porto Alegre: ed. da UFRGS, 2004.

DEHN, M.; BUMA, J. Modeling future landslide activity base on general circulation models. Geomorfology, n. 30, 1999. p. $175-187$.

FIGUEIRÓ, A. S. Mudanças ambientais na interface floresta - cidade e propagação de efeito de borda no Maciço da Tijuca - Rio de Janeiro, RS. 2005. 
Enchentes do Rio Uruguai no Rio Grande do Sul entre 1980 e 2005: uma análise geográfica Eléia Righi, Luis Eduardo de Souza Robaina

398f. Tese (Doutorado em Geografia) - Programa de Pós Graduação em Geografia, Universidade Federal do Rio de Janeiro, Instituto de Geociências, Rio de Janeiro, 2005.

MINISTÉRIO DO MEIO AMBIENTE (MMA). Mapa de biomas do Brasil. Escala 1:5.000.000, 2005.

MIRANDA, J. C. Intercepção das chuvas pela vegetação florestal e serrapilheira nas encostas do maciço da Tijuca, RJ. 1992. 100 f. Dissertação (Mestrado em Geografia) - Programa de PósGraduação em Geografia, UFRJ, Rio de Janeiro,1992.

NIMER, E. Climatologia do Brasil. 2. ed. Rio de Janeiro: IBGE, 1989.

RADAM/IBGE. Mapeamento Geomorfológico Região Hidrográfica do Rio Uruguai. IBGE, 2003.

RECKZIEGEL, B. W. Levantamento dos Desastres Desencadeados por Eventos Naturais Adversos no Estado do Rio Grande do Sul no Período de 1980 a 2005. 2007. V1. Dissertação (Mestrado em Geografia) - Universidade Federal de Santa Maria, Santa Maria, 2007.

RECKZIEGEL, B. W; ROBAINA, L. E. S. Desastres Naturais no Estado do Rio Grande do Sul no Período de 1980 a 2005: Enchentes e Enxurradas. In: II SIBRADEN. Anais..., São Paulo: Santos, 2007.

SOUZA, C. F. Contrastes regionais e formações urbanas. Porto Alegre: Ed. da UFRGS, 2000. (Coleção Síntese Rio-grandense)

TUCCI, C. E. Controle de enchentes. In: TUCCI, C. E. M. (Org.). Hidrologia: ciência e aplicação. Porto Alegre: ABRH/EDUSP, 1993.FIGURA 1: Localização da Bacia do Rio Uruguai no estado do RS. 